\title{
Down-regulation of miR-29c is a prognostic biomarker in acute myeloid leukemia and can reduce the sensitivity of leukemic cells to decitabine
}

Li-juan Tang ${ }^{1,3 \dagger}{ }^{\text {, Guo-kang Sun }}{ }^{1,3+}{ }^{+}$Ting-juan Zhang ${ }^{1,3+}$, De-hong Wu ${ }^{4}$, Jing-dong Zhou ${ }^{1,3}$, Bei-bei Ma ${ }^{1,3}$, Zi-jun Xu ${ }^{1,3}$, Xiang-mei Wen ${ }^{1,3}$, Qin Chen ${ }^{1,3}$, Dong-ming Yao ${ }^{1,3}$, Jun Qian² ${ }^{2^{*}}$, Ji-chun Ma $^{1 *}$ and Jiang Lin ${ }^{{ }^{*}}$

\begin{abstract}
Background: MicroRNA-29c (miR-29c) is abnormally expressed in several cancers and serves as an important predictor of tumor prognosis. Herein, we investigate the effects of abnormal miR-29c expression and analyze its clinical significance in acute myeloid leukemia (AML) patients. In addition, decitabine (DAC) has made great progress in the treatment of AML in recent years, but DAC resistance is still common phenomenon and the mechanism of resistance is still unclear. We further analyze the influences of miR-29c to leukemic cells treated with DAC.
\end{abstract}

Methods: Real-time quantitative PCR (RQ-PCR) was carried out to detect miR-29c transcript level in 102 de novo AML patients and 25 normal controls. miR-29c/shRNA-29c were respectively transfected into K562 cells and HEL cells. Cell viability after transfection was detected by cell counting Kit-8 assays. Flow cytometry was used to detect apoptosis.

Results: MiR-29c was significantly down-regulated in AML $(P<0.001)$. Low miR-29c expression was frequently observed in patients with poor karyotype and high risk ( $P=0.006$ and 0.013 , respectively). Patients with low miR-29c expression had a markedly shorter overall survival (OS) than those with high miR-29c expression $(P<0.001)$. Multivariate analysis confirmed the independent prognostic value of low miR-29c expression in both the whole cohort as well as the cytogenetically normal AML (CN-AML) subset. Over-expression of miR-29c in K562 treated with DAC inhibited growth, while silencing of miR-29c in HEL promoted growth and inhibited apoptosis. MiR-29c overexpression decreased the half maximal inhibitory concentration $\left(I C_{50}\right)$ of DAC in $\mathrm{K} 562$, while miR-29c silencing increased the $I C_{50}$ of DAC in HEL. The demethylation of the miR-29c promoter was associated with its up-regulated expression. Although miR-29c demethylation was also observed in DAC-resistant K562 (K562/DAC), miR-29c expression was down-regulated. MiR-29C transfection also promoted apoptosis and decreased the $I_{50}$ of DAC in K562/DAC cells.

Conclusions: Our results suggest that miR-29c down-regulation may act as an independent prognostic biomarker in AML patients, and miR-29c over-expression can increase the sensitivity of both non-resistant and resistant of leukemic cells to DAC.

Keywords: MiR-29c expression, Acute myeloid leukemia, Prognostic, Decitabine

\footnotetext{
*Correspondence: qianjun0007@hotmail.com; majichun606@163.com;

linjiangmail@sina.com

†Li-juan Tang, Guo-kang Sun and Ting-juan Zhang contributed equally to

this work

${ }^{1}$ Laboratory Center, Affiliated People's Hospital of Jiangsu University, 8

Dianli Rd., Zhenjiang 212002, People's Republic of China

2 Department of Hematology, Affiliated People's Hospital of Jiangsu

University, 8 Dianli Rd., Zhenjiang 212002, People's Republic of China

Full list of author information is available at the end of the article
} 


\section{Background}

Acute myeloid leukemia (AML) is a malignant tumor of myeloid progenitor cells. It is characterized by the rapid growth of abnormal white blood cells in the bone marrow, which interferes with the production of normal blood cells. The pathogenesis involves the inhibition of cell differentiation, uncontrolled proliferation, abnormal apoptosis and so on $[1,2]$. Despite recent advances in the molecular basis of leukemia and the use of new chemotherapy regimens, the overall outlook of AML remains poor. It has been well established that occurrence of leukemia is the result of different genetic changes, which ultimately leads to malignant transformation [3]. Epigenetic modifications such as DNA methylation and microRNA (miRNAs) expression also play a key role in the pathogenesis and progression of leukemia [4-9]. MicroRNAs are a class of endogenous, non-coding RNAs with regulatory functions that are about 20 to 25 nucleotides in length $[10,11]$. Only a small fraction of the biological functions of miRNAs are currently elucidated. These miRNAs regulate cell growth, tissue differentiation, and thus are involved in development and disease during life $[11,12]$. Over the last decade, many studies have confirmed that deregulated miRNAs activity can be responsible for hematologic malignancies [13, 14]. Some miRNAs may be used as potentially prognostic biomarkers. Alterations in the expression of miR-29, miR-125, miR-126, miR-142, miR-146 and miR-155 have been reported to play a role in the pathogenesis and progression of AML [15-17]. Let-7 family and the miRNA-34 family are known as tumor suppressor miRNAs in B cell lymphoma [18]. MiR-15, miR-16, miR 29a/b and miR-127 are also deregulated in chronic lymphocytic and AML $[18,19]$. Gong et al. found intravenous injection of miR29a/b/c could significantly ameliorate leukemia symptoms in AML model mice and revealed a key role for the miR-29 family in the development of AML [20]. MiR29c, a member of microRNA-29 family, is located on chromosome lq32.2 [21-23]. Prominently, miR-29c has been shown to act as a tumor suppressor gene in various tumors and participate in the regulation of target genes of several important signaling pathways [24-28]. Butrym et al. found that miR-29c expression was up-regulated in older AML patients [29]. However, we got the opposite conclusion in this study. Therefore, this study further elucidates the roles of miR-29c in vitro with special attention to AML.

Additionally, DNA methylation changes are another pathological mechanism in leukemia progression. DNA hypomethylating agents (HMAs), including decitabine and azacitidine (AC), have achieved a considerable clinical role during these years [30,31]. Studies have shown that HMAs exerts anti-tumor activity by re-activating methylation-silenced genes at low doses; whereas it plays a major role in cytotoxicity at high doses [32]. Moreover, responses in some patients are rather low, and these patients are often ephemeral-lived after HMAs failure. During the last few years, the molecular mechanism of anti-methylation therapy has not yet reached a consensus. Studies have shown that high MLL5 expression might increase the sensitivity to DAC in AML cells [33]. HMAs reduced the methylation level of the programmed death 1 (PD-1) promoter in AML cells, which was accompanied by worse survival [34]. Intriguingly, BCL2/adenovirus E1B $19 \mathrm{kDa}$ interacting protein 3-like (BNIP3L) protein could promote apoptosis, but BNIP3L silencing slightly strengthens the apoptotic effect of decitabine in U937 cells [35]. These studies provide a new perspective for clinical and experimental research. Simultaneously, it is necessary to identify certain molecules that can distinguish between patient who will benefit from HMAs therapy and those who will not.

In the present study, we aimed to investigate the expression and methylation levels of miR-29c in leukemic cells. We further evaluated the clinical significance of deregulated miR-29c expression. To date, this study was the first to investigate whether miR-29c was associated with DAC resistance.

\section{Methods \\ Study population}

The present study included 102 newly diagnosed AML patients and 25 healthy donors. The patients were classified according to World Health Organization (WHO) criteria and French-American-British (FAB) classification. Table 1 listed the clinical characteristics of patients. BM mononuclear cells (BMMNCs) were extracted from BM specimens by gradient centrifugation (TBD Sciences, Tianjin, China). Mutations in FLT3, N/K-RAS, and U2AF1 were detected by high-resolution melting analysis [36-38].

\section{RNA extraction, reverse transcription and real-time quantitative PCR (RQ-PCR)}

According to the reagent specification, total RNA was isolated using Trizol reagent (Invitrogen, Carlsbad, CA, USA). RNA was reverse-transcribed to complementary DNA (cDNA) using miScript reverse transcription kit (Qiagen, Duesseldorf, Germany). The procedure of reverse transcription and RQ-PCR was conducted as previously reported $[39,40]$. The forward primers for miR29c were $5^{\prime}$-TAGCACCATTTGAAATCGGTTA- $3^{\prime}$ and the reverse primers were universal primer provided by the manufacturer (miScript). 
Table 1 Correlation between miR-29c expression and patients' parameters

\begin{tabular}{|c|c|c|c|}
\hline \multirow[t]{2}{*}{ Patient's parameters } & \multicolumn{3}{|c|}{ Status of $m i R-29 c$ expression } \\
\hline & Low $(n=51)$ & High $(n=51)$ & $P$ \\
\hline Sex, male/female & $31 / 20$ & $29 / 22$ & 0.423 \\
\hline Median age, years (range) & $54(19-93)$ & $58(18-87)$ & 0.968 \\
\hline Median WBC, $\times 10^{9} / \mathrm{L}$ (range) & $12(1.1-201)$ & $8.1(0.3-528)$ & 0.517 \\
\hline Median hemoglobin, g/L (range) & $76.5(34-138)$ & $71(32-113)$ & 0.202 \\
\hline Median platelets, $\times 10^{9} / \mathrm{L}$ (range) & $42(3-447)$ & $37(4-399)$ & 0.196 \\
\hline BM blasts, \% (range) & $53(6.5-94.5)$ & $42.5(1.0-97.5)$ & 0.085 \\
\hline FAB classification & & & 0.002 \\
\hline Mo & 1 & 0 & \\
\hline M1 & 5 & 4 & \\
\hline M2 & 23 & 24 & \\
\hline M3 & 1 & 14 & \\
\hline M4 & 14 & 6 & \\
\hline M5 & 6 & 3 & \\
\hline M6 & 1 & 0 & \\
\hline WHO classification & & & 0.007 \\
\hline $\mathrm{t}(8 ; 21)$ & 7 & 5 & \\
\hline$t(15 ; 17)$ & 1 & 13 & \\
\hline AML without maturation & 4 & 4 & \\
\hline AML with maturation & 18 & 18 & \\
\hline Acute myelomonocytic leukemia & 15 & 7 & \\
\hline Acute monoblastic and monocytic leukemia & 5 & 2 & \\
\hline Acute erythroid leukemia & 1 & 0 & \\
\hline No data & 0 & 2 & \\
\hline Risk classification & & & 0.013 \\
\hline Low & 8 & 20 & \\
\hline Intermediate & 35 & 23 & \\
\hline High & 8 & 4 & \\
\hline No data & 0 & 4 & \\
\hline Karyotype & & & 0.006 \\
\hline Normal & 27 & 18 & \\
\hline $\mathrm{t}(8 ; 21)$ & 7 & 7 & \\
\hline$t(15 ; 17)$ & 1 & 13 & \\
\hline $11 q 23$ & 1 & 0 & \\
\hline Complex & 7 & 4 & \\
\hline Others & 8 & 5 & \\
\hline No data & 0 & 4 & \\
\hline \multicolumn{4}{|l|}{ Gene mutation* } \\
\hline C-KIT $( \pm)$ & $2 / 47$ & $1 / 47$ & 1.000 \\
\hline $\mathrm{FLT3}( \pm)$ & $7 / 42$ & $6 / 42$ & 1.000 \\
\hline NPM1 $( \pm)$ & $5 / 44$ & $5 / 43$ & 1.000 \\
\hline C/EBPA $( \pm)$ & $7 / 42$ & $5 / 43$ & 0.759 \\
\hline $\mathrm{N} / \mathrm{K}-\mathrm{RAS}( \pm)$ & $3 / 46$ & $4 / 45$ & 1.000 \\
\hline $\mathrm{IDH} 1 / 2( \pm)$ & $3 / 46$ & $3 / 40$ & 0.704 \\
\hline DNMT3A $( \pm)$ & $6 / 43$ & $3 / 40$ & 0.494 \\
\hline U2AF1 ( \pm$)$ & $1 / 48$ & $4 / 39$ & 0.332 \\
\hline$C R( \pm)$ & $33 / 17$ & $26 / 21$ & 0.305 \\
\hline
\end{tabular}

WBC white blood cells, $F A B$ French-American-British classification, $A M L$ acute myeloid leukemia, $C R$ complete remission

+ : positive; - : negative

* +: bi-allelicmutation; -: mono-allelic mutation or wild type 
DNA isolation, chemical modification, and Bisulfite sequencing PCR (BSP)

Genomic DNA was isolated and modified using genomic DNA Purification Kit according to the instructions (Gentra, Minneapolis, MN, USA). The primers for the methylated of miR-29c promoter were $5^{\prime}$-TAG TAGTGGTTGTTTGTTTTTTTGA-3' ${ }^{\prime}$ (forward) and 5 -CCACTCTACTAAAAACTCCATCTCC-3' (reverse). BSP conditions were conducted at $98{ }^{\circ} \mathrm{C}$ for $10 \mathrm{~s}, 40$ cycles for $10 \mathrm{~s}$ at $98{ }^{\circ} \mathrm{C}, 30 \mathrm{~s}$ at $65^{\circ} \mathrm{C}, 30 \mathrm{~s}$ at $72{ }^{\circ} \mathrm{C}$ and followed by a final $7 \mathrm{~min}$. at $72{ }^{\circ} \mathrm{C}$. Then the company sequenced five independent clones from each sample (BGI Tech Solutions Co., Shanghai, China).

\section{Cell line, cell culture, DAC treatment, plasmid construction and transfection}

Cell lines (including K562, HEL, THP-1, HL60, SHI-1 and NB4) were purchased from American Type Culture Collection (Manassas, VA, USA). The K562/DAC was constructed in our laboratory [41]. Cells were cultured in Roswell Park Memorial Institute-1640 (RPMI-1640, Wisent) containing 10\% fetal calf serum (FBS, ExCellBio) and $100 \mathrm{U} / \mathrm{ml}$ penicillin/streptom with $5 \% \mathrm{CO}_{2}$ at $37{ }^{\circ} \mathrm{C}$. The plasmids were designed and synthesized by GenePharma company (Shanghai, China). MiRNA (miR-29c) and shRNA (shRNA-29c) were transfected into cells using HiperFect (Qiagen). The stably transfected cells were selected by Geneticin (G418) or Blasticidin (Invivogen Company) and flow sorting (BD FACSAriall). Then cells were harvested and detected miR-29c expression by RQ-PCR.

\section{Cell viability assays}

Cells (including K562-NC, K562-miR-29c, HEL-NC and shRNA-29c-HEL cells) were seeded at $3 \times 10^{3}$ cells per well in 96-well plate containing complete culture solution and $1 \mu \mathrm{M}$ DAC. After culturing for $0,24 \mathrm{~h}$, $48 \mathrm{~h}$, and $72 \mathrm{~h}$, each well added $10 \mathrm{ul}$ CCK-8 solution. The optical density (OD) was measured by microplate reader.

\section{Half maximal inhibitory concentration $\left(\mathrm{IC}_{\mathbf{5 0}}\right)$ detection}

Cells $\left(3 \times 10^{3}\right.$ cells/well $)$ were seeded onto a 96-well plate containing complete culture solution and different concentration of DAC. The drug concentration was $0 \mu \mathrm{M}, 0.125 \mu \mathrm{M}, 0.25 \mu \mathrm{M}, 0.5 \mu \mathrm{M}, 1 \mu \mathrm{M}, 2 \mu \mathrm{M}$ successively. Cells were cultured for $48 \mathrm{~h}$. OD value detection method was the same as cell viability assays.

\section{Cell apoptosis assays}

Cells $\left(5 \times 10^{5}\right.$ cells/well $)$ were seeded onto a 6-well plate containing complete 1640 culture solution (without FBS solution). After $48 \mathrm{~h}$, the apoptosis rate was detected by apoptosis detection kit (Annexin V PE/7-AAD, BD, 559763) and then analyzed by flow cytometry (BD FACSCalibur, San Jose, CA, USA).

\section{Statistical analysis}

Data analysis was performed using SPSS 20.0 software and GraphPad Prism 5 software. Relative levels of miR$29 \mathrm{c}$ expression were calculated by $2^{-\Delta \Delta C T}$ method. The categorical variables were analyzed using Chi square test and/or Fisher's exact test. The diagnostic value of gene expression was analyzed using receiver operating characteristic curve (ROC curve) and area under the curve (AUC). Kaplan-Meier analysis and Cox regression analyses (univariate and multivariate) were used to analyze the survival. $\mathrm{IC}_{50}$ value was calculated by Probit regression analysis. Data analysis results for all experiments were statistically significant $(P<0.05$, bilateral distribution).

\section{Results}

The level of miR-29c expression in normal controls and $A M L$ patients

From RQ-PCR analysis, the median level of miR-29c expression was different in the normal control and AML groups (0.5703 and 0.2137, respectively). MiR-29c expression was significantly lower in AML compared with normal controls $(P<0.001)$ (Fig. 1a).

\section{Distinguishing capacity of MiR-29c expression}

ROC curve was performed to determine the discriminative capacity of miR-29c expression. The AUC value of miR-29c was 0.753 (95\% CI $0.689-0.874, P<0.001)$ in all AML patients and 0.763 in CN-AML patients $(95 \% \mathrm{CI}$ $0.647-0.878, P<0.001$ ) (Fig. 1b, c), which suggested that miR-29c expression might serve as a potential biomarker in distinguishing AML patients from controls.

\section{Correlation between miR-29c expression and clinical characteristics in AML}

To investigate the clinical relevance of miR-29c expression in AML, the whole patients were divided into two groups (low-expression and high-expression) by the cut off value of 0.187 (sensitivity $60 \%$, specificity $80 \%$ ) based on ROC curve. No significant differences were observed in age, BM blast cell percentage, gender, WBC (white blood cells), $\mathrm{Hb}$ (hemoglobin), PLT (blood platelet) and nine common gene mutations between the two groups $(P>0.05)$. However, obvious differences between the two groups were observed in karyotype and risk classification $(P=0.006$ and 0.013 , respectively). There was no correlation between the common gene mutations and miR-29c expression $(P>0.05)$. 

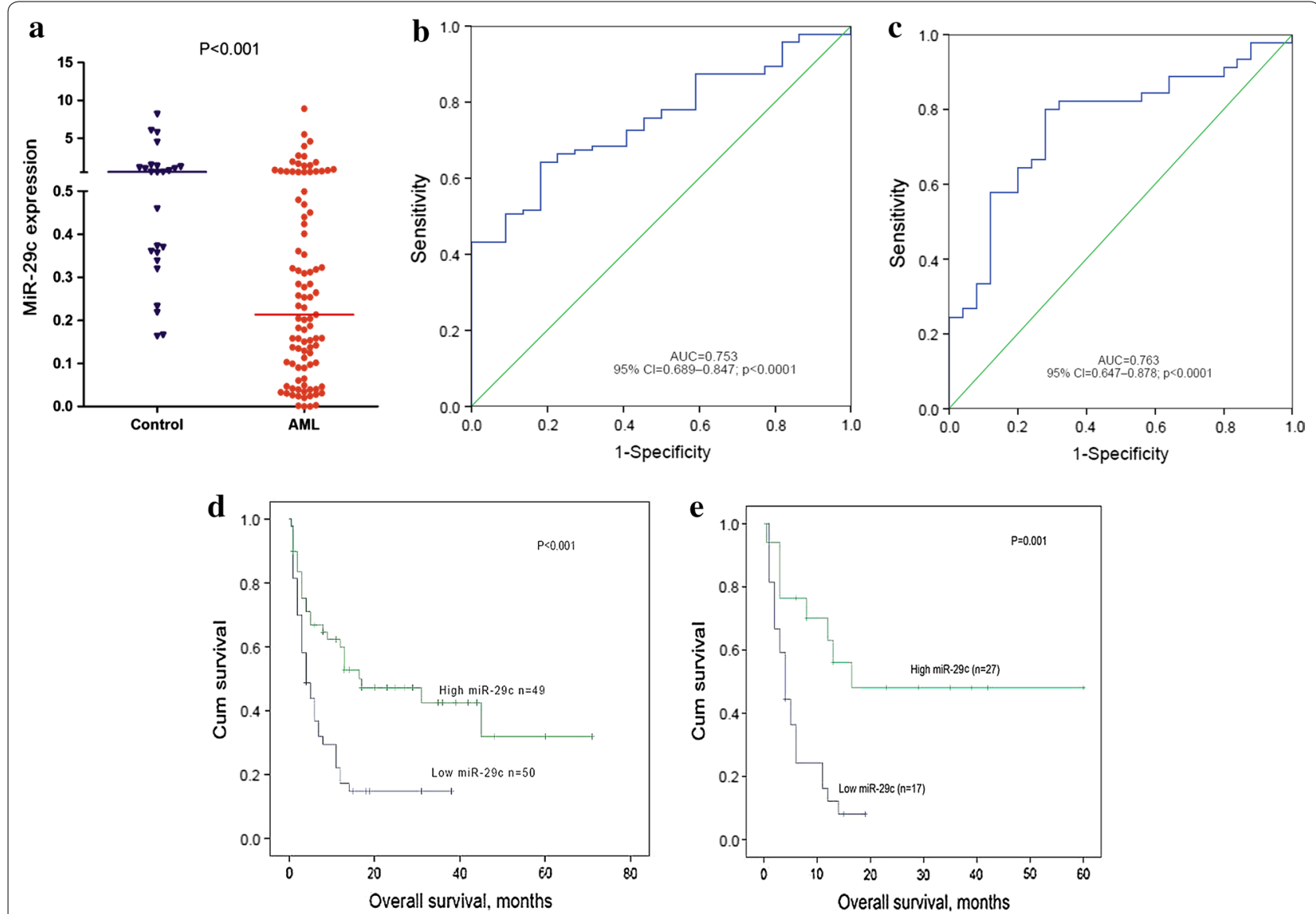

Fig. 1 Expression level of miR-29c and impact of miR-29c expression on OS in AML patients. a The level of miR-29c expression in controls and AML patients by RQ-PCR. $\mathbf{b}$ Discriminative capacity of miR-29c expression by ROC curve analysis for miR-29c AML patients. c Discriminative capacity of miR-29c expression by ROC curve analysis for CN-AML patients. $\mathbf{d}$ Prognostic value of miR-29c expression in whole AML patients. e Prognostic value of miR-29c expression in CN-AML patients. Overall survival (OS) was analyzed between miR-29c high and miR-29c low groups

\section{Effect of miR-29c expression on the outcome of AML patients}

In order to explore the prognostic value of miR-29c in AML, survival data were obtained for 99 AML patients with follow-up data ranged from 1 to 70 months. Although miR-29c has no predicting value on complete remission (CR), patients with low miR-29c expression have markedly shorter OS time in both the whole AML cohort and the CN-AML subset $(P<0.001$, Fig. 1 d). Furthermore, similar results were observed in CN-AML patients $(P<0.001$, Fig. 1e). Multivariate analysis showed the adverse effect of miR-29c low-expression on the outcome. Variables in the univariate analysis with $P<0.2$ (WBC, age, and miR-29c expression, karyotype, K/NRAS mutation, U2AF1 mutation) were included in the multivariate analysis. Importantly, the results showed that miR-29c might be an independent prognostic molecule affecting patients' survival in all AML $(P=0.033)$ or CN-AML $(P=0.020$, Tables 2 and 3$)$.

\section{MiR-29c increased sensitivity to DAC and promoted apoptosis in leukemic cells}

Before performing cell function experiments, we detected the expression levels of miR-29c in different leukemic cells, and found that miR-29c expression was decreased in K562, THP-1, HL60 and increased in HEL (Fig S1 in Additional file 1). Therefore, we selected HEL with the highest expression of miR-29c for gene gain-of-function. Additionally, we obtained DAC-resistant cells of K562. K562 cells were selected for gene loss-of-function. Increased expression of miR29c in K562-miR-29c cells and decreased expression of miR-29c in shRNA-29c-HEL cells were confirmed by RQ-PCR (Fig. S2A, B in Additional file 1). The growth rate of K562-miR-29c was significantly lower than that of the K562-NC cells $(P<0.001$, Fig. 2a, b). Similarly, the growth rate of shRNA-29c-HEL was obviously higher than that of the HEL-NC cells $(P<0.001$, Fig. 2 d, e). Moreover, miR-29c overexpression decreased the 
Table 2 Univariate and multivariate analyses of prognostic factors for overall survival in whole-cohort AML patients

\begin{tabular}{|c|c|c|c|c|}
\hline \multirow[t]{2}{*}{ Prognostic factors } & \multicolumn{2}{|l|}{ Univariate analysis } & \multicolumn{2}{|l|}{ Multivariate analysis } \\
\hline & Hazard ratio $(95 \% \mathrm{Cl})$ & $P$ value & Hazard ratio $(95 \% \mathrm{Cl})$ & $P$ value \\
\hline Age $(>60 / \leq 60$ year $)$ & $2.840(1.708-4.723)$ & $<0.001$ & $1.381(0.553-3.449)$ & 0.489 \\
\hline WBC $\left(\geq 30 \times 10^{9} /<30 \times 10^{9} / L\right)$ & $2.111(1.424-3.127)$ & $<0.001$ & $1.572(0.420-4.132)$ & 0.381 \\
\hline karyotype grouping & $1.932(1.567-2.383)$ & $<0.001$ & $1.967(1.375-2.841)$ & 0.001 \\
\hline miR-29c expression & $2.398(1.427-4.032)$ & 0.001 & $2.336(1.026-5.319)$ & 0.033 \\
\hline KNN-RAS mutation $( \pm)$ & $1.622(0.840-3.131)$ & 0.150 & $1.115(0.147-8.467)$ & 0.916 \\
\hline U2AF1 mutation $( \pm)$ & $1.814(0.732-4.500)$ & 0.199 & $1.014(0.492-5.806)$ & 0.986 \\
\hline FLT3 mutation $( \pm)$ & $1.109(0.577-2.132)$ & 0.757 & - & - \\
\hline
\end{tabular}

+: positive; -: negative

Table 3 Univariate and multivariate analyses of prognostic factors for overall survival in CN-AML patients

\begin{tabular}{|c|c|c|c|c|}
\hline \multirow[t]{2}{*}{ Prognostic factors } & \multicolumn{2}{|l|}{ Univariate analysis } & \multicolumn{2}{|l|}{ Multivariate analysis } \\
\hline & Hazard ratio $(95 \% \mathrm{Cl})$ & $P$ value & Hazard ratio $(95 \% \mathrm{Cl})$ & $P$ value \\
\hline Age & $2.080(1.017-4.255)$ & 0.045 & $1.125(0.262-4.825)$ & 0.874 \\
\hline WBC & $1.522(0.852-2.718)$ & 0.049 & $1.174(0.305-4.505)$ & 0.816 \\
\hline miR-29c expression & $3.546(1.548-8.130)$ & 0.003 & $6.897(1.362-34.483)$ & 0.020 \\
\hline KN-RAS mutation $( \pm)$ & 1.395 (0.548-3.550) & 0.485 & - & - \\
\hline FLT3 mutation $( \pm)$ & 1.185 (0.503-2.793) & 0.697 & - & - \\
\hline U2AF1 mutation $( \pm)$ & $1.181(0.574-2.452)$ & 0.651 & - & - \\
\hline
\end{tabular}

+: positive; -: negative

$\mathrm{IC}_{50}$ value of DAC in $\mathrm{K} 562$, while miR-29c silencing increased the $\mathrm{IC}_{50}$ of DAC in HEL (Fig. 2c, f). The overall apoptotic rate of shRNA-29c-HEL cells was significantly lower than that of HEL-NC cells $(P<0.001$, Fig. 2g-i).

\section{Decreased expression of miR-29c might be involved in DAC} resistance

To analyze the relationship of miR-29c expression and DAC resistance, the expression and promoter methylation of miR-29c were detected by RQ-PCR and BSP separately in K562 and K562/DAC cells. Results showed that the expression of miR-29c was up-regulated with increased DAC concentration in K562 cells $(P<0.01$, Fig. 3a). The methylation density of the miR$29 \mathrm{c}$ promoter region was reduced (Fig. 3c). Although demethylation change was also observed in the miR29c promoter region in K562/DAC cells (Fig. 3d), the level of miR-29c expression was down-regulated (Fig. 3b). This suggested DAC resistance was accompanied with miR-29c down-regulation.
High miR-29c expression could increase the sensitivity of DAC-resistant cells to DAC

Increased expression of miR-29c in K562/DAC-miR-29c was confirmed by RQ-PCR (Fig. S3A in Additional file 1). Similarly, the viability rate of K562/DAC-miR-29c cells was significantly lower than that of the K562/DAC-NC cells $(P<0.001$, Fig. $4 \mathrm{a}, \mathrm{b})$. The $\mathrm{IC}_{50}$ value of $\mathrm{K} 562 / \mathrm{DAC}$ miR-29c cells was significantly lower than that of the K562/DAC-NC cells $(P<0.001$, Fig. 4c). Furthermore, the apoptosis assays showed that the apoptotic rate of $\mathrm{K} 562 /$ DAC-miR-29c cells was significantly higher than that of K562/DAC cells $(P<0.001$, Fig. $4 d$, Fig. S3B, C in Additional file 1$)$. The above results suggested that the miR29c gene might alter the reactivity of DAC-resistant cells to DAC.

\section{Discussion}

MiR-29c has been reported to be down-expressed in human solid tumors, such as breast cancer and lung cancer $[42,43]$. Many studies have proved that miR-29c indeed acts as a tumor suppressor and miR-29c effects on cell proliferation, senescence, apoptosis and progression of cancer [44]. MiR-29c down-regulation was 

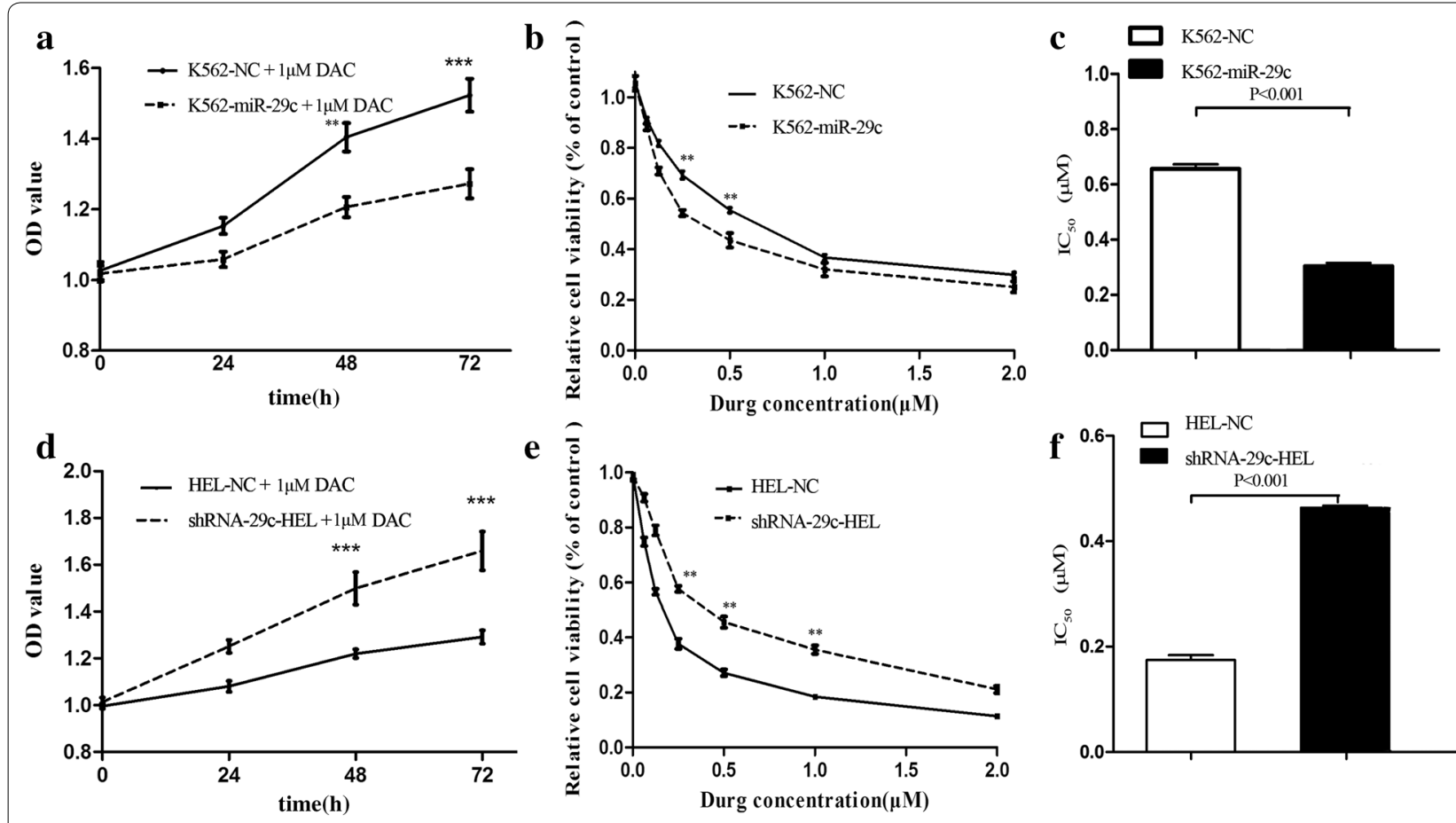

e
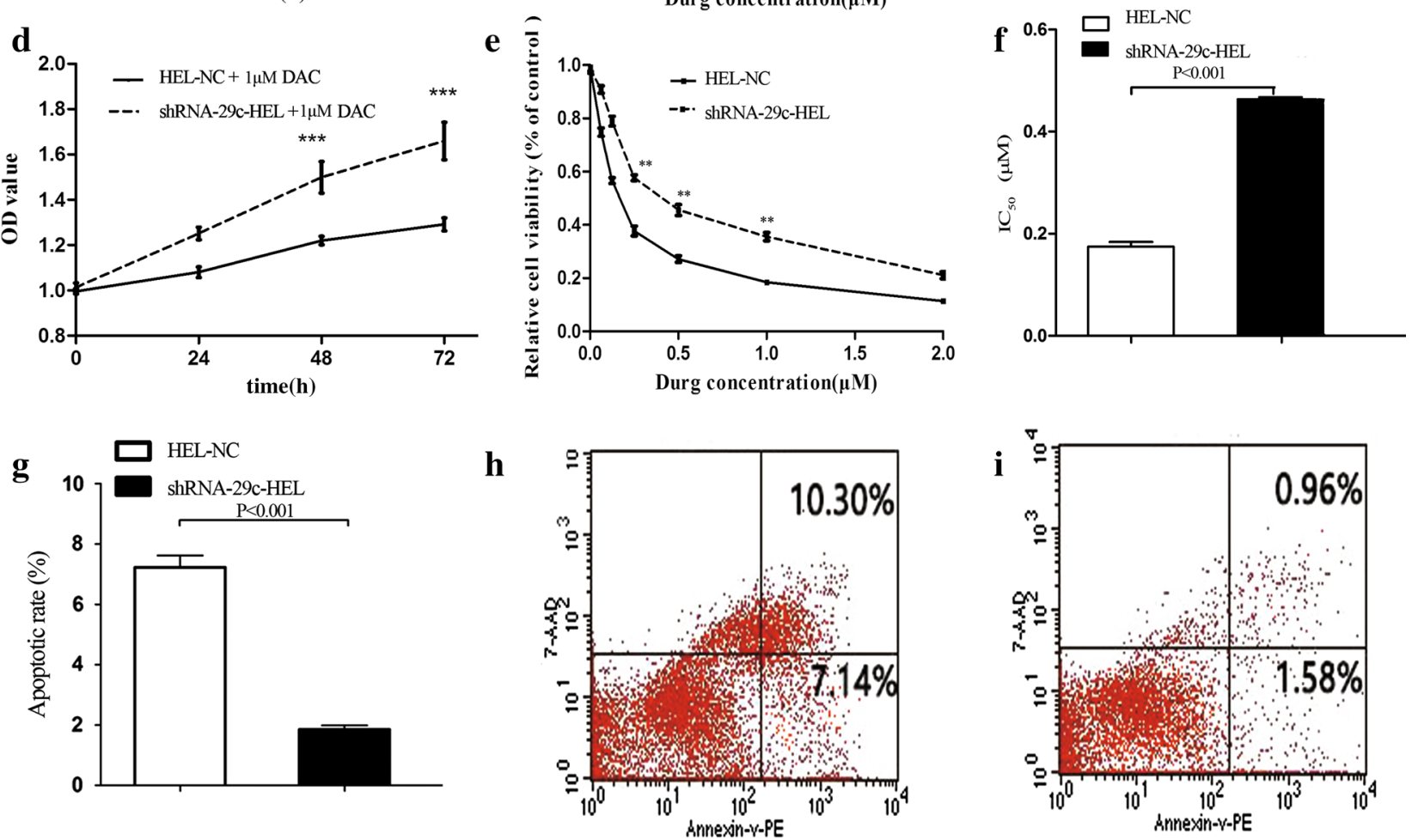

Fig. 2 MiR-29c increased sensitivity to DAC and promoted apoptosis in leukemic cells. a CCK-8 Kit analysis the cell viability in K562-NC and K562-miR-29c cells. b, c Analysis the sensitive of DAC in K562-NC and K562-miR-29c cells by CCK-8 Kit. d CCK-8 Kit analysis the cell viability in HEL-NC and shRNA-29c-HEL cells. e, f Analysis the sensitive of DAC in HEL-NC and shRNA-29c-HEL cells by CCK-8 Kit. $\mathbf{g}$ The statistical analysis of Flow Cytometry about HEL-NC and shRNA-29c-HEL cells. $\mathbf{h}$ The apoptosis rate of HEL-NC cells was detected by Flow Cytometry. i The apoptosis rate of shRNA-29c-HEL cells was detected by Flow Cytometry. The $\mathrm{IC}_{50}$ was the half maximal inhibitory concentration

associated with poor survival in chronic lymphocytic leukemia, acute lymphoblastic leukemia, Burkitt lymphoma and chronic myeloid leukemia [45-48]. Conversely, Zhu et al. found that miR-29c was overexpressed in early stage non-small lung cancer (NSCLC), whereas the level of miR-29c expression did not relate with the OS of NSCLC patients [49]. Butrym et al. found that miR-29c was upregulated and associated with poor prognosis in older AML patients [29]. However, our results showed that miR-29c expression was significantly down-regulated in AML and low expression of miR-29c was associated with shorter overall survival. We thought there were two pivotal reasons for our different results, as follow: (A) Subjects: Butrym et al. contained 95 patients (73 patients with primary leukemia and 22 patients with leukemia secondary to myelodysplastic or myeloproliferative syndrome). Our study included 102 newly diagnosed AML patients. Furthermore, the previous treatment of 22 patients with secondary leukemia was unknown. Namely, there were differences between the two studies' subjects. (B) Treatment regimen: This is a vital factor affecting the prognosis of patients. Drug used by Butrym et al. was 


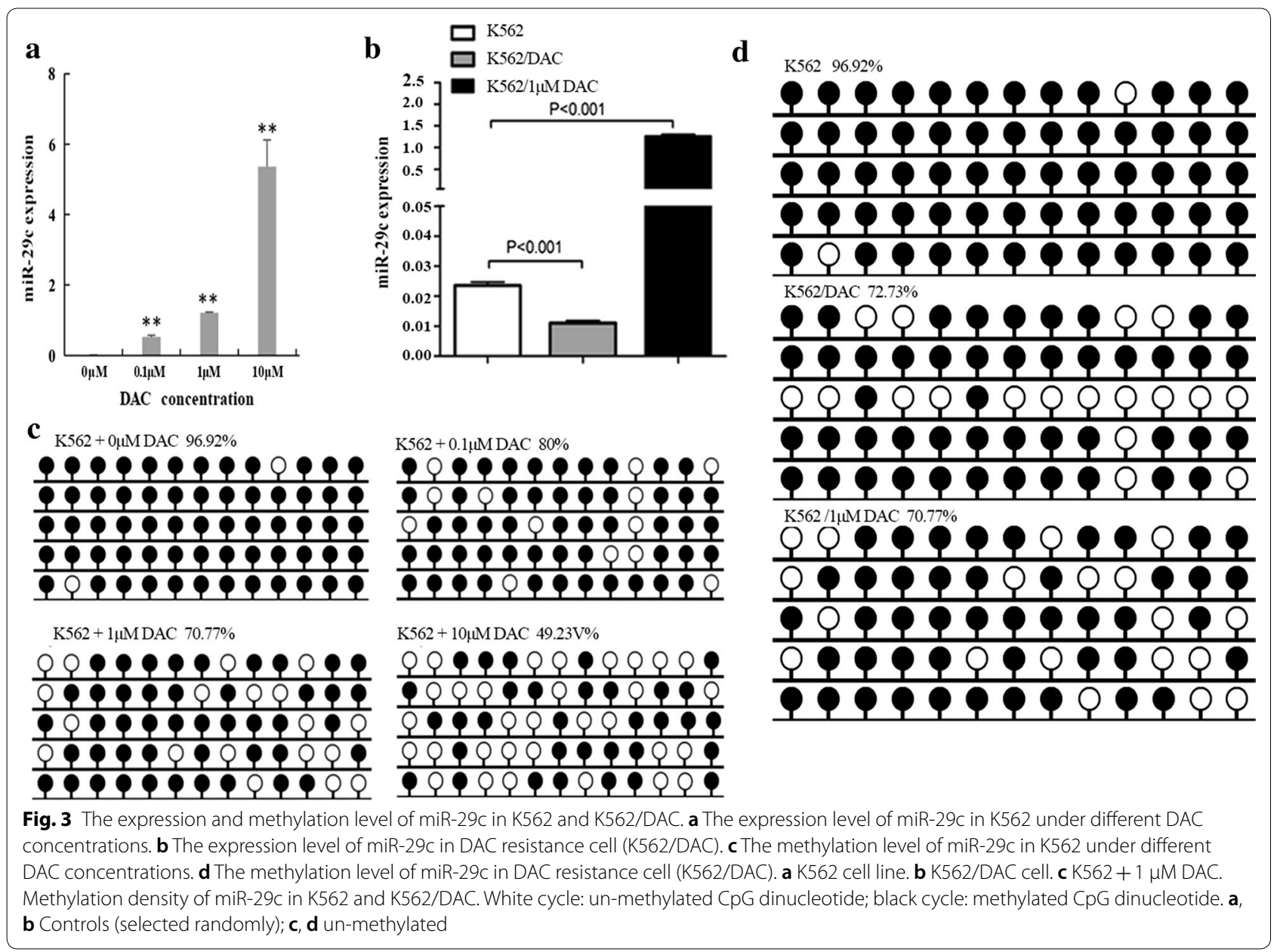

azacitidine. However, the patients were treated with conventional chemotherapy in our study. Additionally, our studies in vitro revealed that miR-29c over-expression could promote apoptosis and inhibited growth in leukemic cells treated with DAC, while miR-29c knock-down could reverse the effect.

In recent years, some miRNAs have been found to take part in chemotherapeutic drugs resistance, such as miR138, miR-194, miR-137, etc. [40-52]. It has been reported that high miR-29c expression increased the sensitivity of non-small cell lung cancer (NSCLC) cells to the cisplatin [53]. Wang et al. found that miR-29c overexpression might contribute to the efficacy of cisplatin in gastric cancer treatment [54]. MiR-29c overexpression increased the sensibility of temozolomide-resistance cells in glioblastoma [55]. In vitro studies, miR-29c up-expression was accompanied with miR-29c demethylation during DAC treatment. It suggested that miR-29c expression might be regulated by its promoter methylation. Although the level of miR-29c expression was down-regulated, the promoter of miR-29c was demethylated in K562/DAC. This suggests that decreased expression of miR-29c may be involved in DAC resistance, which could be reversed by miR-29c over-expression.

\section{Conclusions}

Taken together, our results indicate that down-regulation of miR-29c is a frequent event and predicts poor prognosis in de novo AML patients. MiR-29c overexpression can increase the sensitivity of leukemic cells to DAC and provides possible guidance for clinical DAC resistance. 

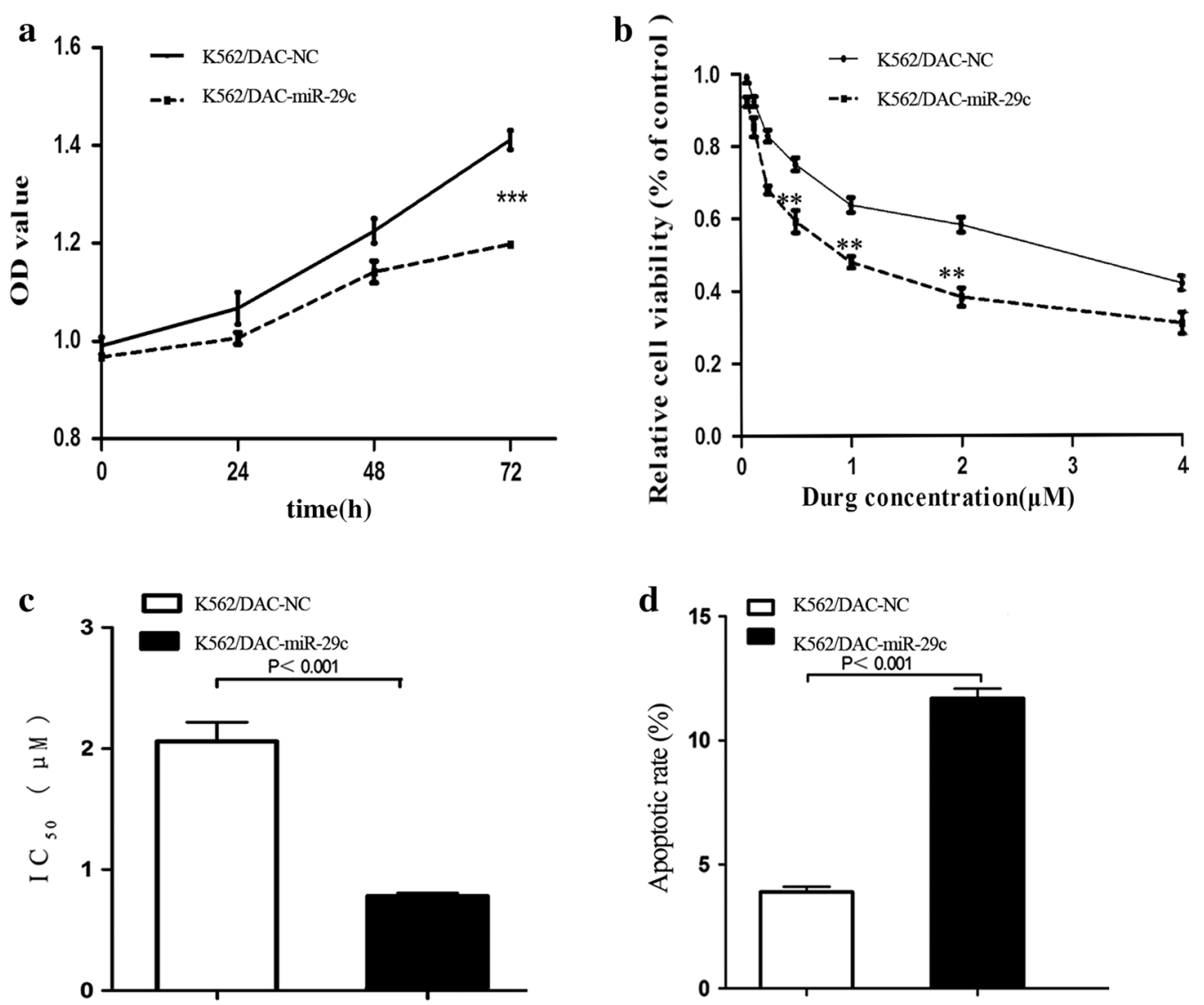

Fig. 4 MiR-29c increased sensitivity to DAC and promoted apoptosis in DAC-resistant leukemic cells. a CCK-8 Kit analysis the cell viability in K562/ DAC-NC and K562/DAC-miR-29c cells. b, c Analysis the sensitive of DAC in K562/DAC-NC and K562/DAC-miR-29c cells by CCK-8 Kit. d The statistical analysis of flow cytometry about K562/DAC-NC and K562/DAC-miR-29c cells cells. The IC ${ }_{50}$ was the half maximal inhibitory concentration

\section{Additional file}

Additional file 1. Additional figures.

\section{Abbreviations}

DAC: decitabine, 5-Aza-2'-deoxycytidine; HMAs: hypomethylating agents; AC: azacitidine; RQ-PCR: real-time quantitative PCR; AML: acute myeloid leukemia; ROC curve: receiver operating characteristic curve; OS: overall survival; $C R$ : complete remission; BSP: bisulfite sequencing PCR; CN-AML: cytogenetically normal AML; HEL-NC: HEL cells transduced with the plasmid of Neo-shNC; shRNA-29c-HEL: HEL cells transduced with the plasmid of homo-shRNA-29c; K562-NC: K562 cells transduced with the plasmid of Neo-shNC; K562-miR-29c: K562 cells transduced with the plasmid of homo-miR-29c; K562/DAC: K562 cells were resistant to DAC; K562/DAC-NC: K562/DAC cells transduced with the plasmid of Neo-shNC; K562/DAC-miR-29c: K562/DAC cells transduced with the plasmid of homo-miR-29c; IC 50 : the half maximal inhibitory concentration.

\section{Acknowledgements}

The authors would like to thank the supporting staff and patients the in this study.

\section{Authors' contributions}

$J Q$, JL and JM designed the experiments; LT, GS and XW performed the experiments; LT, TZ, DW, JZ, BM and ZX collected and analyzed the clinical data; QC and DY were involved in the interpretation of the results. LT, GS and TZ wrote the paper. All authors read and approved the final manuscript.

\section{Funding}

This study was supported by National Natural Science foundation of China (81270630), Medical Innovation Team of Jiangsu Province (CXTDB2017002), 333 Project of Jiangsu Province (BRA2016131), Six talent peaks project in Jiangsu Province (2015-WSN-115), China Postdoctoral Science Foundation funded project (2016M601748), youth medical talents project of "Ke Jiao Qiang Wei" project of Jiangsu province (QNRC2016450, QNRC2016449), "Liu Ge Yi Gong Cheng" of Jiangsu Province (LGY2018024), Zhenjiang Clinical Research Center of Hematology (SS2018009), Social Development Foundation of Zhenjiang (SH2017040, SH2018044), Social Development Foundation of Kunshan (KS1624), "Postgraduate Research \& Practice Innovation Program of Jiangsu Province" (KYCX17_1821, KYCX18_2281), Key Medical Talent Program of Zhenjiang City.

\section{Availability of data and materials}

The datasets used and/or analyzed during the current study are available from the corresponding author on reasonable request.

\section{Ethics approval and consent to participate}

This study was approved by the Ethics Committee and Institutional Review. Board of the Affiliated People's Hospital of Jiangsu University (NO: 20120016). Written informed consents were obtained from all registered individuals prior to their participation.

\section{Consent for publication}

The authors agree for publication. 


\section{Competing interests}

The authors declare that they have no competing interests.

\section{Author details}

${ }^{1}$ Laboratory Center, Affiliated People's Hospital of Jiangsu University, 8 Dianli Rd., Zhenjiang 212002, People's Republic of China. ${ }^{2}$ Department of Hematology, Affiliated People's Hospital of Jiangsu University, 8 Dianli Rd., Zhenjiang 212002, People's Republic of China. ${ }^{3}$ The Key Lab of Precision Diagnosis and Treatment of Zhenjiang City, Zhenjiang, Jiangsu, People's Republic of China. ${ }^{4}$ Department of Hematology, The Third People's Hospital of Kunshan City, 615 Zizhu Rd, Kunshan 215300, People's Republic of China.

Received: 14 January 2019 Accepted: 27 June 2019

Published online: 10 July 2019

\section{References}

1. Bowman RL, Busque L, Levine RL. Clonal Hematopoiesis and evolution to hematopoietic malignancies. Cell Stem Cell. 2018;22:157-70.

2. Eaves CJ. A prospective analysis of human leukemogenesis. Stem Cell Rep. 2018;11:1034-9.

3. Jimenez-Morales S, Hidalgo-Miranda A, Ramirez-Bello j. Acute lymphoblastic leukemia: a genomic perspective. Bol Med Hosp Infant Mex. 2017;74:13-26.

4. Ley TJ, Miller C, Ding L, Raphael BJ, Mungall AJ. Genomic and epigenomic landscapes of adult de novo acute myeloid leukemia. N Engl J Med. 2013;368:2059-74.

5. Figueroa ME, Lugthart S, Li Y, Erpelinck-Verschueren C, Deng X, Christos PJ, Schifano E, Booth J, van Putten W, Skrabanek L, Campagne F, Mazumdar M, Greally JM, Valk PJ, Löwenberg B, Delwel R, Melnick A. DNA methylation signatures identify biologically distinct subtypes in acute myeloid leukemia. Cancer Cell. 2010;17(1):13-27.

6. Yan F, Shen N, Pang JX, Zhao N, Zhang YW, Bode AM, Al-Kali A, Litzow MR, Li B, Liu SJ. A vicious loop of fatty acid-binding protein 4 and DNA methyltransferase 1 promotes acute myeloid leukemia and acts as a therapeutic target. Leukemia. 2018;32:865-73.

7. Tarighat SS, Santhanam R, Frankhouser D, Radomska HS, Lai H, Anghelina $M$, et al. The dual epigenetic role of PRMT5 in acute myeloid leukemia: gene activation and repression via histone arginine methylation. Leukemia. 2016;30:789-99.

8. Mansouri L, Wierzbinska JA, Plass C, Rosenquist R. Epigenetic deregulation in chronic lymphocytic leukemia: clinical and biological impact. Semin Cancer Biol. 2018;51:1-11.

9. Rupaimoole R, Slack FJ. MicroRNA therapeutics: towards a new era for the management of cancer and other diseases. Nat Rev Drug Discov. 2017; 16:203-22.

10. Wallace JA, O'Connell RM. MicroRNAs and acute myeloid leukemia: therapeutic implications and emerging concepts. Blood. 2017;130:1290-301.

11. Liu Y, Cheng Z, Pang Y, Cui L, Qian T, Quan L, Zhao H, Shi J, Ke X, Fu L. Role of microRNAs, circRNAs and long noncoding RNAs in acute myeloid leukemia. J Hematol Oncol. 2019;12:51.

12. Diaz-Beya M, Brunet $S$, Nomdedeu J, Tejero R, Diaz T, Pratcorona M, Tormo M, Ribera JM, Escoda L, Duarte R, Gallardo D, Heras I, Queipo de Llano MP, Bargay J, Monzo M, Sierra J, Navarro A, Esteve J. MicroRNA expression at diagnosis adds relevant prognostic information to molecular categorization in patients with intermediate-risk cytogenetic acute myeloid leukemia. Leukemia. 2014;28:804-12.

13. Bertoli G, Cava C, Castiglioni I. MicroRNAs: new biomarkers for diagnosis, prognosis, therapy prediction and therapeutic tools for breast cancer. Theranostics. 2015;5:1122-43.

14. Aziz H, Ping CY, Alias H, AbMutalib NS, Jamal R. Gene mutations as emerging biomarkers and therapeutic targets for relapsed acute myeloid leukemia. Front Pharmacol. 2017;8:897.

15. Khalaj M, Tavakkoli M, Stranahan AW, Park CY. Pathogenic microRNA's in myeloid malignancies. Front Genet. 2014;5:361.

16. Garzon R, Heaphy CE, Havelange V, Fabbri M, Volinia S, Tsao T, Zanesi N, Kornblau SM, Marcucci G, Calin GA, Andreeff M, Croce CM. MicroRNA 29b functions in acute myeloid leukemia. Blood. 2009;114(26):5331-41.

17. Lechman ER, Gentner B, Ng SW, Schoof EM, Van Galen P, Kennedy JA, Nucera S, Ciceri F, Kaufmann KB, Takayama N, Dobson SM, Trotman-Grant
A, Krivdova G, Elzinga J, Mitchell A, Nilsson B, Hermans KG, Eppert K, Marke R, Isserlin R, Voisin V, Bader GD, Zandstra PW, Golub TR, Ebert BL, Lu J, Minden M, Wang JC, Naldini L, Dick JE. miR-126 regulates distinct selfrenewal outcomes in normal and malignant hematopoietic stem cells. Cancer Cell. 2016;29:214-28.

18. Blandino G, Fazi F, Donzelli S, Kedmi M, Sas-Chen A, Muti P, Naldini L, Paola M, Sabrina S, Yosef Y. Tumor suppressor microRNAs: a novel non-coding alliance against cancer. FEBS Lett. 2014;588:2639-52.

19. Nucera S, Giustacchini A, Boccalatte F, Calabria A, Fanciullo C, Plati T, Ranghetti A, Garcia-Manteiga J, Cittaro D, Benedicenti F, Lechman E, Dick J, Ponzoni M, Ciceri F, Montini E, Gentner B. MiRNA-126 orchestrates an oncogenic program in B cell precursor acute lymphoblastic leukemia. Cancer Cell. 2016:29:905-21.

20. Gong JN, Yu J, Lin HS, Zhang XH, Yin XL, Xiao Z, Wang F, Wang XS, Su R, Shen C, Zhao HL, Ma YN, Zhang JW. The role, mechanism and potentially therapeutic application of microRNA-29 family in acute myeloid leukemia. Cell Death Differ. 2014;21:100-12.

21. Jiang $\mathrm{H}$, Zhang $\mathrm{G}, \mathrm{Wu} \mathrm{JH}$, Jiang CP. Diverse roles of miR-29 in cancer (review). Oncol Rep. 2014;31:1509-16.

22. Zhang S, Jin J, Tian X, Wu L. Hsa-miR-29c-3p regulates biological function of colorectal cancer by targeting SPARC. Oncotarget. 2017;8:104508-24.

23. Sengupta S, den Boon JA, Chen IH, Newton MA, Stanhope SA, Cheng YJ, et al. MicroRNA 29c is down-regulated in nasopharyngeal carcinomas, up-regulating mRNAs encoding extracellular matrix proteins. Proc Natl Acad Sci USA. 2008;105:5874-8.

24. Negrini M, Cutrona G, Bassi C, Fabris S, Zagatti B, Colombo M, Ferracin M, D'Abund L, Saccenti E, Matis S, Lionetti S, Agnelli L, Gentile M, Recchia AG. MicroRNA expression in chronic lymphocytic leukemia: comparison with normal B-cell subsets and correlations with prognostic and clinical parameters. Clin Cancer Res. 2014;20:4141-53.

25. Cui H, Wang L, Gong P, Zhao C, Zhang S, Zhang K, Zhou R, Zhao Z, Fan H. Deregulation between miR-29b/c and DNMT3A is associated with epigenetic silencing of the $\mathrm{CDH} 1$ gene, affecting cell migration and invasion in gastric cancer. PLoS ONE. 2015;10:e0123926.

26. Wang Y, Liu C, Luo M, Zhang Z, Gong J, Li J, You L, Dong L, Su R, Lin H, Ma Y, Wang F, Wang Y, Chen J, Zhang J, Jia H, Kong Y, Yu J. Chemotherapyinduced miRNA-29c/Catenin-delta signaling suppresses metastasis in gastric cancer. Cancer Res. 2015;75:1332-44.

27. Yamada Y, Sugawara S, Arai T, Kojima S, Kato M, Okato A, Yamazaki K, Naya Y, Ichikawa T, Seki N. Molecular pathogenesis of renal cell carcinoma: impact of the anti-tumor miR-29 family on gene regulation. Int J Urol. 2018:25:953-65.

28. Li J, Fu F, Wan X, Huang S, Wu D, Li Y. Up-regulated miR-29c inhibits cell proliferation and glycolysis by inhibiting SLC2A3 expression in prostate cancer. Gene. 2018;665:26-34.

29. Butrym A, Rybka J, Baczynska D, Poreba R, Kuliczkowski K, Mazur G. Clinical response to azacitidine therapy depends on microRNA-29c (miR-29c) expression in older acute myeloid leukemia (AML) patients. Oncotarget. 2016;7:30250-7.

30. Kubasch A, Platzbecker U. Beyond the edge of hypomethylating agents: novel combination strategies for older adults with advanced MDS and AML. Cancers. 2018;6:158.

31. Ferrara F. Guadecitabine: a new therapeutic option for acute myeloid leukaemia ? Lancet Oncol. 2017;18:1287-8.

32. Qin T, Jelinek J, Si J, Shu J, Issa JPJ. Mechanisms of resistance to 5-aza-2'deoxycytidine in human cancer cell lines. Blood. 2008;113:659-67.

33. Yun H, Damm F, Yap D, Schwarzer A, Chaturvedi A, Jyotsana N, Lubbert M, Bullinger L, Dohner K, Geffers R, Aparicio S, Humphries RK, Ganser A, Heuser M. Impact of MLL5 expression on decitabine efficacy and DNA methylation in acute myeloid leukemia. Haematologica. 2014;9:1456-64.

34. Yang H, Bueso-Ramos C, DiNardo C, Estecio MR, Davanlou M, Geng QR, Fang Z, Nguyen M, Pierce S, Wei Y, Parmar S, Cortes J, Kantarjian H, GarciaManero G. Expression of PD-L1, PD-L2, PD-1 and CTLA4 in myelodysplastic syndromes is enhanced by treatment with hypomethylating agents. Leukemia. 2014;6:1280-8.

35. Lazarini M, Machado-Neto JA, Duarte AD, Pericole FV, Vieira KP, Niemann FS, Alvarez M, Traina F, Saad ST. BNIP3L in myelodysplastic syndromes and acute myeloid leukemia: impact on disease outcome and cellular response to decitabine. Haematologica. 2016;101:e445-8. 
36. Qian J, Yao DM, Lin J, Qian W, Wang CZ, Chai HY, Yang J, Li Y, Deng ZQ, Ma $J C$, Chen XX. U2AF1 mutations in Chinese patients with acute myeloid leukemia and myelodysplastic syndrome. PLoS ONE. 2012;7:e45760.

37. Lin J, Yao DM, Qian J, Chen Q, Qian W, Yang J, Wang CZ, Chai HY, Qia Z, Xiao GF, Xu WR. IDH1 and IDH2 mutation analysis in Chinese patients with acute myeloid leukemia and myelodysplastic syndrome. Ann Hematol. 2012;91:519-25.

38. Zhou JD, Wang YX, Zhang TJ, Li XX, Gu Y, Zhang W, Ma JC, Lin J, Qian J. Identification and validation of SRY-box containing gene family member SOX30 methylation as a prognostic and predictive biomarker in myeloid malignancies. Clin Epigenetics. 2018;10:92.

39. Zhou JD, Yang L, Zhang YY, Yang J, Wen XM, Guo H, Yao DM, Ma JC, Chen Q, Lin J, Qian J. Overexpression of BAALC: clinical significance in Chinese de novo acute myeloid leukemia. Med Oncol. 2015;1:386.

40. Zhou JD, Lin J, Zhang TJ, et al. Hypomethylation-mediated H19 overexpression increases the risk of disease evolution through the association with BCR-ABL transcript in chronic myeloid leukemia. J Cell Physiol. 2018:32:2444-50

41. Wen XM, Zhang TJ, Ma JC, Zhou JD, Xu ZJ, Zhu XW, Yuan Q, Ji RB, Chen Q, Deng ZQ, Lin J, Qian J. Establishment and molecular characterization of decitabine-resistant K562 cells. J Cell Mol Med. 2019. https://doi. org/10.1111/jcmm.14221.

42. Han TS, Hur K, Xu G, Choi B, Okugawa Y, Toiyama Y, Oshima H, Oshima M, Lee HJ, Kim VN, Chang AN, Goel A, Yang HK. MicroRNA-29c mediates initiation of gastric carcinogenesis by directly targeting ITGB1. Gut. 2015;64:203-14.

43. Jiang J, Yu C, Chen M, Zhang H, Tian S, Sun C. Reduction of miR-29c enhances pancreatic cancer cell migration and stem cell-like phenotype. Oncotarget. 2015;20:2767-78

44. Li W, Yi J, Zheng X, Liu S, Fu W, Ren L, Li L, Hoon DS, Wang J, Du G. MiR-29c plays a suppressive role in breast cancer by targeting the TIMP3/STAT1/ FOXO1 pathway. Clin Epigenetics. 2018;10:64.

45. Marcucci G, Haferlach T, Dohner H. Molecular genetics of adult acute myeloid leukemia: prognostic and therapeutic implications. J Clin Oncol. 2011;29(5):475-86.

46. Lyu G, Guan Y, Zhang C, Zong L, Sun L, Huang X, Huang L, Zhang L, Tian $X \mathrm{~L}$, Zhou Z, Tao W. TGF-beta signaling alters H4K20me3 status via miR-29 and contributes to cellular senescence and cardiac aging. Nat Commun. 2018;9:4134.
47. Almeida RS, Costa ESM, Coutinho LL, Garcia Gomes R, Pedrosa F, Massaro JD, et al. MicroRNA expression profiles discriminate childhood T- from B-acute lymphoblastic leukemia. Hematol Oncol. 2019;37:103-12.

48. Ferreira AF, Moura LG, Tojal I, Ambrosio L, Pinto-Simoes B, Hamerschlak N, Calin GA, Ivan C, Covas DT, Kashima S, Castro FA. ApoptomiRs expression modulated by BCR-ABL is linked to CML progression and imatinib resistance. Blood Cells Mol Dis. 2014:53:47-55.

49. Zhu W, He J, Chen D, Zhang B, Xu L, Ma H, Liu X, Zhang Y, Le H. Expression of miR-29c, miR-93, and miR-429 as potential biomarkers for detection of early stage non-small lung cancer. PLoS ONE. 2014;9:e87780.

50. Rastgoo N, Pourabdollah M, Abdi J, Reece D, Chang H. Dysregulation of EZH2/miR-138 axis contributes to drug resistance in multiple myeloma by downregulating RBPMS. Leukemia. 2018. https://doi.org/10.1038/ s41375-018-0140-y.

51. Aversana C, Giorgio C, Amato L, Lania G, Matarese F, Saeed S, Saeed S, Costanzo D, Ingenito C, Martens JHA. MiR-194-5p/BCLAF1 deregulation in AML tumorigenesiss. Leukemia. 2018;32:573.

52. Qin Y, Zhang S, Deng S, An G, Qin X, Xu Y, Hao M, Yang Y, Zhou W, Chang $\mathrm{H}$, Qiu L. Epigenetic silencing of miR-137 induces drug resistance and chromosomal instability by targeting AURKA in multiple myeloma. Leukemia. 2017;31:1123-35.

53. Sun DM, Tang BF, Li ZX, Guo HB, Cheng JL, Song PP, Zhao X. MiR-29c reduces the cisplatin resistance of non-small cell lung cancer cells by negatively regulating the PI3K/Akt pathway. Sci Rep. 2018;8:8007.

54. Patel JP, Gonen M, Figueroa ME, Fernandez H, Sun Z, Racevskis J, Van Vlierberghe P, Dolgalev I, Thomas S, Aminova O, Huberman K, Cheng J. Prognostic relevance of integrated genetic profiling in acute myeloid leukemia. N Engl J Med. 2012;366:1079-89.

55. Luo H, Chen Z, Wang S, Zhang R, Qiu W, Zhao L, Peng C, Xu R, Chen W, Wang HW, Chen Y, Yang J, Zhang X, Zhang S, Chen D, Wu W, Zhao C, Cheng G, Jiang T, Lu D, You Y, Liu N, Wang H. C-Myc-miR-29c-REV3L signalling pathway drives the acquisition of temozolomide resistance in glioblastoma. Brain. 2015;138:3654-72.

\section{Publisher's Note}

Springer Nature remains neutral with regard to jurisdictional claims in published maps and institutional affiliations.
Ready to submit your research? Choose BMC and benefit from:

- fast, convenient online submission

- thorough peer review by experienced researchers in your field

- rapid publication on acceptance

- support for research data, including large and complex data types

- gold Open Access which fosters wider collaboration and increased citations

- maximum visibility for your research: over $100 \mathrm{M}$ website views per year

At BMC, research is always in progress.

Learn more biomedcentral.com/submissions 